\title{
Cyanobacteria, BMAA e ELA
}

Walter G Bradley*, Paul A Cox, John Pablo, Sandra Banack, Spyros Papapetropoulos, Holly Johnson, Deborah Mash

*Presenter, DM, FRCP, Professor and Chairman Emeritus, Miller School of Medicine, University of Miami, Miami, FL, USA

Paul Cox et al. have demonstrated that cyanobacteria in the roots of the cycad palm produce a neurotoxic non-protein amino acid, BMAA that is bio-concentrated up the food chain to humans suffering from the Guamanian type of 'neurodegenerative' disease, the ALS/Parkinson-Dementia Complex. Also, they have shown that: (1) Cyanobacteria producing neurotoxins, including BMAA, are concentrated in the estuary and source of drinking water of Hohara village in the Kii Peninsula of Japan, where the incidence of ALS/PDC is at least as high as in Guam. (2) Cyanobacteria producing BMAA are ubiquitous throughout the world. (3) Cyanobacteria are associated with 'algal blooms' in areas of water associated with human use and animal deaths.

Deborah Mash et al. in the University of Miami have independently confirmed that protein-bound BMAA is present in the brains of Florida, USA patients with Alzheimer's disease (12 cases, mean level of $111 \pm 14.6 \mu \mathrm{g} / \mathrm{g}$ ), with Parkinson's disease (2 cases, 176 and $218 \mu \mathrm{g} / \mathrm{g}$ ), and with amyotrophic lateral sclerosis (13 brains, mean level of $134 \pm 12.8 \mu \mathrm{g} / \mathrm{g} ; 4$ spinal cords, mean level $124 \pm 69 \mu \mathrm{g} / \mathrm{g}$ ). Age-matched brains of patients dying with non-neurological conditions contained only trace amounts of BMAA (12 cases with two specimens, 22 negative and 2 positive -45 and $36 \mu \mathrm{g} / \mathrm{g}$ ). Brains from Huntington disease patients, used as disease controls, contained only trace amounts of BMAA ( 8 cases, 7 negative and one positive $-11 \mu \mathrm{g} / \mathrm{g}$ ). 


\section{SIMPÓSIO BRASILEIRO DE DNM/ELA}

Our continuing studies are investigating the roles of environmental exposure and genetic predisposition in producing this disease-related accumulation of BMAA, the mechanism of individual accumulation of BMAA in brain proteins, and the production of animal models of BMAA neuro-intoxication. Therapeutic opportunities based upon the BMAA hypothesis of the environmental neurotoxin responsible for age-related neurodegenerations will be discussed. 